DOI: 10.12731/2218-7405-2018-7-76-89

УДК 316.628.23

\title{
ПСИХОЛОГИЧЕСКИЕ УСЛОВИЯ СНИЖЕНИЯ МОТИВАЦИИ ПЕРСОНАЛА ПОД ВЛИЯНИЕМ ВНЕШНЕГО ВОЗДЕЙСТВИЯ
}

\author{
Борисова И.И.
}

Цель исследования. Статья посвящена изучению внешних психологических условий, сниюающих мотивацию работника к осуществлению профессиональной деятельности. Задачами исследования являются: изучение отрицательного влияния внешних факторов на трудовые мотивы и описание негативных психологических особенностей условий снижения эффективности мотивационных воздействий.

Методология проведения работы. Произведен анализ литературы и использованы эмпирические методы в процессе исследования. Метод исследования - тестирование испытуемых. После проведения тестирования полученные результаты подверглись статистической обработке в программе $R$.

Результаты. Выявлена корреляция между внешней мотиваџией и психологическими факторами. Сделаны выводы о негативном воздействии внешних психологических факторов на снижение мотивации к осущчествлению эффективной профессиональной деятельности.

Определены психологические условия, снижающие мотивацию работника, и предложены рекомендации для руководителей компаний.

Область применения результатов. Результаты могут быть использованы управленческим аппаратом компаний.

Ключевые слова: профессиональная деятельность; внешняя положительная мотивация; психологические факторы; персонал; руководитель. 


\section{THE PSYCHOLOGICAL CONDITIONS OF EFFICIENCY OF EXTERNAL MOTIVATION}

\section{Borisova I.I.}

Research objective. The article is devoted to studying the external psychological conditions reducing the motivation of the worker to an implementation of professional activity. Research problems are: studying of the negative influence of external factors on labour motives and description of negative psychological features of conditions of a decrease in efficiency of motivational influences.

The methodology of the work. The analysis of literature is made and empirical methods in the course of the research are used. A research method-testing of examinees. After conducting testing the received results have undergone statistical processing in the program $R$.

Results. The correlation between external motivation and psychological factors is revealed. Conclusions are drawn on the negative impact of external psychological factors on a decrease in motivation to an implementation of effective professional activity. Psychological conditions that decrease motivation of a worker are defined and recommendations for heads of the companies are offered.

The scope of results application. Results can be used by administrative personnel of the companies.

Keywords: professional activity; external positive motivation; psychological factors; personnel; leader.

\section{Введение}

В современных условиях осуществления профессиональной деятельности для работников остается важным не только высокий и справедливый уровень заработной платы и соблюдение трудового законодательства, но и психологические аспекты, такие как: самореализация, признание, социальный статус, свобода, стабильность, комфортные условия труда, а также одобрение и поддержка со стороны руководителя. Руководители современных компаний осозна- 
ют, что нужно побуждать работников к эффективной деятельности как материально, так и нематериально, но не все знают, какие психологические ошибки в процессе управления могут нивелировать внешнее положительное стимулирование. Поэтому необходимо не только знать, но и устранять негативные факторы, снижающие мотивацию персонала.

На сегодняшний день существуют множество теорий, отражающих концепции влияния на мотивацию профессиональной деятельности человека, к ним относятся: иерархическая теория мотивации А. Маслоу, «теория Х» и «теория Ү» Д. Мак-Грегора, теория справедливости С. Адамса, теория ожиданий В. Врума, двухфакторная мотивационно-гигиеническая теория Ф. Герцберга и другие [2]. Эти теории легли в основу эмпирических и теоретических исследований вопроса мотивации человека в процессе осуществления профессиональной деятельности в работах отечественных ученых: Гордеева Т.О. [1], Дубовик Ю.В. [3], Котов С.В. [5], Мингалёва Ж.А., Депутатова Л.Н. [6], Пырьева Е.А. [7] и других. Исследование данного вопроса проводились также современными зарубежными исследователями: L. George [14], A. Elliot и M. Church [12], D. Popescu, I. Buleі и V. Mihalcioiu [13], B. Kuvaas, R. Buch, A. Weibel, A. Dysvik и C. Nerstad [15]. Среди этих исследований не рассматриваются факторы, оказывающие негативное влияние на мотивацию к осуществлению профессиональной деятельности. Изучение факторов, оказывающих негативное влияние на мотивацию, позволяет находить, обосновывать средства и методы, применяемые в процессе составления мотивационной системы, но и исследовать психологические особенности поведения человека и отношений в некомфортных условиях работы.

\section{Организация, выборка и методика исследования}

С целью изучения психологических условий, оказывающих негативное влияние на снижение мотивации к осуществлению эффективной профессиональной деятельности работниками различных компаний, проведено эмпирическое исследование психологиче- 
ских внешних факторов. Объект исследования - человек, работающий на предприятии, обладающий профессиональными навыками и умениями, а также имеющий соответствующую квалификацию и специальность. Предмет исследования - психологические условия, оказывающие негативное воздействие на мотивацию профессиональной деятельности. Гипотеза исследования: к психологическим условиям, снижающим эффективность внешней мотивации, относятся несправедливо установленный уровень заработной платы, отношение руководителя к выполняемым функциям работника, условия психологического давления на сотрудника и ограничения, нарушение условий и режима труда, отсутствие возможности к росту и развитию.

Эмпирическое исследование психологических условий негативного воздействия на работников проводилось в коммерческих организациях. В исследовании принимали участие 50 испытуемых в возрасте от 22 до 57 лет, работающих в организациях различных сфер. Группа испытуемых была сформирована по соответствию с заданным критерием - осуществление профессиональной деятельности. Выборка является репрезентативной и совокупной.

Для исследования связи внешних негативных психологических условий и мотивации осуществления профессиональной деятельности применены следующие методики: методика диагностики личности на мотивацию к успеху Т. Элерса; методика диагностики личности на мотивацию к избегание неудач Т. Элерса; методика диагностики социально-психологических установок личности в мотивационно-потребностной сфере О.Ф. Потемкиной; методика «Мотивация профессиональной деятельности» К. Замфир; методика «Выявление потребности отдельных лиц и выявления мотивационных пластов в организации»; методика диагностики «Рейтинг ценностно-потребностях ориентаций персонала» [4]; методика диагностики самооценки мотивации одобрения (шкала лживости) Д. Марлоу и Д. Крауна; методика «Диагностика мотивационной структуры личности» В.Э. Мильман; методика диагностики направленности личности Б. Басса (ориентационная анкета) $[9,11]$. 


\section{Результаты исследования}

По итогам проведенной батареи методик произведено распределение полученных результатов по шкалам, данные приведены в таблице 1.

Таблицуа 1.

Распределение результатов батареи методик по шкалам

\begin{tabular}{|c|c|c|c|c|}
\hline Методика & Шкалы & $\begin{array}{l}\text { Низкий } \\
\text { балл, \% }\end{array}$ & $\begin{array}{l}\text { Средний } \\
\text { балл, \% }\end{array}$ & $\begin{array}{c}\text { Высокий } \\
\text { балл, \% }\end{array}$ \\
\hline 1 & 2 & 3 & 4 & 5 \\
\hline $\begin{array}{l}\text { Стремление } \\
\text { к успеху Т. Элекрс }\end{array}$ & Стремление к успеху & 5 & 69 & 26 \\
\hline $\begin{array}{l}\text { Избегание неудач } \\
\text { Т. Элерс }\end{array}$ & Избегание неудач & 5 & 64 & 31 \\
\hline \multirow{3}{*}{$\begin{array}{l}\text { Методика изуче- } \\
\text { ния мотивации } \\
\text { профессиональ- } \\
\text { ной деятельности } \\
\text { Замфир }\end{array}$} & Внутренняя мотивация & 5 & 59 & 36 \\
\hline & $\begin{array}{l}\text { Внешняя положительная } \\
\text { мотивация }\end{array}$ & 10 & 57 & 33 \\
\hline & $\begin{array}{l}\text { Внешняя отрицательная } \\
\text { мотивация }\end{array}$ & 29 & 31 & 40 \\
\hline \multirow{8}{*}{$\begin{array}{l}\text { Методика диагно- } \\
\text { стики социально- } \\
\text { психологических } \\
\text { установок лично- } \\
\text { сти в мотивацион- } \\
\text { но-потребнойст- } \\
\text { ной сфере О.Ф. } \\
\text { Потемкина }\end{array}$} & Ориентация на процесс & 2 & 79 & 19 \\
\hline & Ориентация на результат & 7 & 79 & 14 \\
\hline & Ориентация на альтруизм & 19 & 57 & 24 \\
\hline & Ориентация на эгоизм & 43 & 24 & 33 \\
\hline & Ориентация на труд & 29 & 61 & 10 \\
\hline & Ориентация на свободу & 5 & 76 & 19 \\
\hline & Ориентация на власть & 45 & 36 & 19 \\
\hline & Ориентация на деньги & 38 & 36 & 26 \\
\hline \multirow{5}{*}{\begin{tabular}{|l} 
Выявление по- \\
требности от- \\
дельных лиц и \\
выявления моти- \\
вационных пласто \\
в организации
\end{tabular}} & Материальные потребности & 26 & 45 & 29 \\
\hline & $\begin{array}{l}\text { Потребности } \\
\text { в безопасности }\end{array}$ & 24 & 45 & 31 \\
\hline & $\begin{array}{l}\text { Социальные (межличностные) } \\
\text { потребности }\end{array}$ & 40 & 20 & 40 \\
\hline & Потребности в признании & 31 & 38 & 31 \\
\hline & \begin{tabular}{|l} 
Потребности \\
в самовыражении
\end{tabular} & 31 & 31 & 38 \\
\hline
\end{tabular}


Окончание табл. 1.

\begin{tabular}{|c|c|c|c|c|}
\hline $\begin{array}{l}\text { Методика диагно- } \\
\text { стики «Рейтинг } \\
\text { ценностно-по- } \\
\text { требностных } \\
\text { ориентаций пер- } \\
\text { сонала» }\end{array}$ & $\begin{array}{l}\text { Ценностно-потребностные } \\
\text { ориентации }\end{array}$ & 36 & 19 & 45 \\
\hline $\begin{array}{l}\text { Методика диа- } \\
\text { гностики само- } \\
\text { оценки мотива- } \\
\text { ции одобрения } \\
\text { (шкала лживости) } \\
\text { Д. Марлоу } \\
\text { и Д. Крауна }\end{array}$ & Мотивация одобрения & 40 & 39 & 21 \\
\hline \multirow{7}{*}{$\begin{array}{l}\text { Диагностика } \\
\text { мотивационной } \\
\text { структуры лично- } \\
\text { сти Мильван }\end{array}$} & Жизнеобеспечение & 21 & 53 & 26 \\
\hline & Комфорт & 21 & 58 & 21 \\
\hline & Социальный статус & 29 & 38 & 33 \\
\hline & Общение & 26 & 43 & 31 \\
\hline & Общая активность & 26 & 45 & 29 \\
\hline & Творческая активность & 24 & 52 & 24 \\
\hline & Социальная полезность & 29 & 47 & 24 \\
\hline \multirow{3}{*}{$\begin{array}{l}\text { Методика диагно- } \\
\text { сти направленно- } \\
\text { сти личности } \\
\text { Т. Басса } \\
\end{array}$} & Я (Направленность на себя) & 33 & 31 & 36 \\
\hline & О (Направленность на общение) & 40 & 27 & 33 \\
\hline & Д (Направленность на дело) & 19 & 57 & 24 \\
\hline
\end{tabular}

После обработки ответов испытуемых определены показатели средних значений по группе.

Приведенные в таблице 1 результаты отображают, что для группы испытуемых характерен средний уровень мотивации к достижению успеха и избегания неудач. Преобладает большой процент испытуемых в группе (57\%) с баллом по шкале «избегание неудач». Он выше, чем по шкале стремления к успеху. Это определяет характерное для преобладающей части группы испытуемых желание избежать неудачи, наказания, санкций, чем стремление достичь успеха в своей профессиональной деятельности. Данный факт подтверждает высокое количество экстремально высоких значений по шкале «Внешняя отрицательная мотивация» (40\%).

По шкалам методики диагностики Потемкиной максимальный процент экстремально малых значений включает в себя следую- 
щие показатели: Ориентация на власть (45\%), Ориентация на эгоизм (43\%). Экстремально высоких значений шкал данной методики среди ответов испытуемых не обнаружено.

Среди шкал методики выявления потребности отдельных лиц и выявления мотивационных пластов в организации определены следующие экстремально низкие значения показателей по шкале «Социальные (межличностные) потребности» (40\%), так и экстремально высокие по данной шкале (40\%).

По методике Рейтинг ценностно-потребностных ориентаций персонала выявлено 45\% испытуемых с экстремально высокими значениями. Кроме того, по шкале «Самооценка мотивации одобрения методики диагностики самооценки мотивации одобрения (шкала лживости)» Д. Марлоу и Д. Крауна зафиксировано 40\% испытуемых с экстремально высокими показателями по группе.

По методике диагностики направленности личности Т.Басса экстремально высоких значений не обнаружено, но выявлены экстремально низкие значения среди испытуемых в группе (40\%).

Различий между мужской и женской выборкой не обнаружено.

По коэффициентам корреляции Спирмена и r-критерия Пирсона, рассчитанным с использованием программы $\mathrm{R}$, определены связи между внешней мотивацией и психологическими факторами, оказывающими влияние на профессиональную деятельность человека. Выявленные значимые связи приведены в таблице $2[8,10]$.

Таблица 2.

Показатели корреляции между внешней положительной мотивацией и психологическими факторами

\begin{tabular}{|l|c|c|}
\hline \multicolumn{1}{|c|}{ Фактор } & $\mathbf{~}$ & $\mathbf{p}$ \\
\hline Социальные (межличностные) потребности & $-0,54$ & 0,00 \\
\hline Потребность в жизнеобеспеченья & 0,52 & 0,00 \\
\hline Стремление достижения успеха & 0,42 & 0,01 \\
\hline Внешняя отрицательная мотивация & 0,31 & 0,04 \\
\hline Ориентация на власть & 0,47 & 0,00 \\
\hline Ориентация на деньги & 0,31 & 0,04 \\
\hline Социальный статус & 0,46 & 0,00 \\
\hline
\end{tabular}




\section{Выводы по задачам исследования}

Определена сильная отрицательная связь внешней положительной мотивации и шкалой «Социальные (межличностные) потребности» $(\mathrm{r}=-0,54 ; \mathrm{p}<0,00)$. Чем сильней оказывается негативное воздействие со стороны руководителя на подчиненного, тем больше он стремится к социальной защите путем смены работы или поиска поддержки со стороны коллег, друзей и семьи. В результате отрицательного воздействия на сотрудника снижается мотивация к профессиональной деятельности, но увеличивается желание к жизнедеятельности вне компании, а также возникают конфликты внутри подразделений и между ними. К данной категории негативного воздействия со стороны работодателя можно отнести: чрезмерный надзор за деятельностью работника, неуважительное отношение, нарушение субординации, психологическое ограничение свободы в решениях и деятельности сотрудника, вмешательство в его личную жизнь, слежка, запугивание.

Определена сильная положительная связь внешней положительной мотивации и потребности в жизнеобеспечении $(\mathrm{r}=0,52 ; \mathrm{p}<0,00)$. Низкое жизнеобеспечение оказывает отрицательное воздействие на мотивацию сотрудника к осуществлению эффективной профессиональной деятельности. Уровень своей жизнеобеспеченности человек определяет по отношению к уровню других сотрудников компании, а также коллег, работающих на других предприятиях в такой же или аналогичной должности. К данной категории негативного воздействия со стороны работодателя можно отнести: несправедливое установление заработной платы среди сотрудников, несправедливое распределение должностных обязанностей и нагрузки, предоставление некомфортных условий труда, нарушение режима трудового дня.

Определена умеренная связь стремления достижения успеха и внешней положительной мотивации $(\mathrm{r}=0,42 ; \mathrm{p}<0,01)$. При успешном выполнении поставленной задачи сотрудник ожидает похвалы и поощрения со стороны руководителя за свой результат труда. В случае, если он не получает ожидаемого, то при выполнении следующего поручения мотивация к эффективной деятельности и успешному выполнению задачи будет снижена. К данной категории негатив- 
ного воздействия со стороны работодателя можно отнести: отсутствие положительного подкрепления, стимулирования, похвалы и поддержки со стороны компании или руководителя

Определена умеренная связь внешней отрицательной и внешней положительной мотивации ( $\mathrm{r}=0,31 ; \mathrm{p}<0,04)$. Чем сильнее влияние внешней положительной мотивации, тем эффективней воздействие внешней отрицательной мотивации на эффективность профессиональной деятельности работника. Соответственно при низком уровне внешней положительной мотивации и высоком внешней отрицательной мотивации стремление к осуществлению эффективной профессиональной деятельности у сотрудника снижается, появляется чувство неудовлетворенности и состояние напряжения. В результате работник психологически отделяет себя от компании, начинает искать другое место для работы, желает компании кризисного финансового состояния, а также может возникнуть желание навредить работодателю. При низкой внешней отрицательной мотивации и высокой внешней положительной влияние последней будет снижаться, так как у работника будет происходить психологическое привыкание, соответственно будет снижаться эффективность профессиональной деятельности. К данной категории негативного воздействия со стороны работодателя можно отнести: злоупотребление санкциями, публичные выговоры и порицания, высокая текучесть кадров из-за увольнений по инициативе компании по причине низкой эффективности работника.

Определена умеренная связь ориентации на власть и внешней положительной мотивации ( $\mathrm{r}=0,47 ; \mathrm{p}<0,00)$. Чем ниже уровень внешней положительной мотивации, тем меньше работник стремится к власти и не желает расширять свою область компетенции. К данной категории негативного воздействия со стороны работодателя можно отнести: отсутствие возможности карьерного роста, рамочное ограничение процесса осуществления профессиональной деятельности сотрудником, отсутствие возможности творческого подхода к работе.

Определена умеренная связь ориентации на деньги и внешней положительной мотивации $(\mathrm{r}=0,31 ; \mathrm{p}<0,04)$. При высоком уровне 
ориентации на деньги работник ожидает, что чем больше он усилий вкладывает в решение той или иной задачи, тем больше он заработает. Соответственно, если этот баланс не будет соблюдаться, сотрудник потеряет интерес к работе и будет выполнять текущие задачи менее эффективно. К данной категории негативного воздействия со стороны работодателя можно отнести: отсутствие системы премий и поощрений в компании.

Определена умеренная связь шкалы «Социальный статус» и внешней положительной мотивации ( $\mathrm{r}=0,46 ; \mathrm{p}<0,00)$. Работнику, ориентированному на достижение социального статуса, важно получить признание со стороны коллег и руководства, занимать положение «гуру» в их профессиональной сфере. Посредственное отношение к выполняемым сотрудником функциям приведет к снижению эффективности его профессиональной деятельности. К данной категории негативного воздействия со стороны работодателя можно отнести: занижение или завышение значимости выполняемых функций среди сотрудников и отделов.

Таким образом, основными факторами негативного воздействия являются чрезмерный надзор, нарушение субординации, психологическое ограничение свободы и давление, вмешательство в личную жизнь, несправедливое установление заработной платы и распределения нагрузки, некомфортные условия труда, нарушение режима трудового дня, отсутствие внешнего положительного стимулирование, злоупотребление санкциями, публичные выговоры и порицания, отсутствие карьерного роста и развития, а также пренебрежительное отношение руководителя к труду работника. Из чего следует, что наша гипотеза исследования подтвердилась.

\section{Практические рекомендации}

Чтобы избежать снижения мотивации к осуществлению эффективной профессиональной деятельности персонала необходимо соблюдать рекомендации.

Осуществлять справедливое установление уровня заработной платы среди сотрудников путем составления штатного расписания 
согласно фактической структуре компании, уровню сложности и вида выполняемой работы, квалификации и области ответственности.

Соблюдать требования охраны труда, среди которых важным является оборудование рабочего места всем необходимым для эффективного и безопасного выполнения определенных для сотрудника служебных функций, а также соблюдение режима рабочего дня.

В трудовых взаимоотношениях важно соблюдать субординацию и уважительно относиться к каждому сотруднику независимо от занимаемой им должности и статуса. Руководителю необходимо взаимодействовать с подчиненными с использованием личностного подхода, с соблюдением этических норм и законов, при этом недопустимо отношение к сотрудникам как к ресурсу обогащения предприятия. Кроме того, руководителю необходимо поддерживать равный уровень значимости всех структурных подразделений в хозяйственной деятельности компании.

С целью стимулирования мотивации к осуществлению эффективной профессиональной деятельности сотрудниками необходимо использовать широкую систему премирования, которая будет в себя включать показатели эффективности деятельности работника, основанные на различных критериях оценки: производительность, инновационность, вовлеченность, ответственность, успешное выполнение поставленных задач и так далее.

Сотрудникам необходимо предоставлять возможность карьерного роста и развития внутри компании. Для этого рекомендуется направлять работников на обучение, семинары и тренинги, связанными с функциями, осуществляемыми в процессе профессиональной деятельности того или иного сотрудника. При этом необходимо предоставлять работникам возможность творческого подхода к решению задач путем вынесения предложений и рекомендаций по изменению или улучшению процесса на рассмотрение вышестоящему руководителю. Желательно разбивать долгосрочные задачи на этапы выполнения, при успешном выполнении каждого этапа осуществлять психологическое поощрение сотрудника за хорошо выполненную работу путём похвалы и закреплением достигнутого результата. 


\section{Список литературы}

1. Гордеева Т.О. Базовые типы мотивации деятельности: потребностная модель // Вестник Московского университета. Серия 14: Психология. 2014. №3. С. 63-78.

2. Гуров В. И., Сукманов Э. В. Эволюция теорий мотивации // Вестник Курской государственной сельскохозяйственной академии. 2008. №2.

3. Дубовик Ю.В. Демотивация как обратный эффект мотивации: зарубежная и Российская практика // Электронный вестник Ростовского социально-экономического института. 2016. №2.

4. Замфир К. Удовлетворенность трудом. М.: Политиздат, 1983.

5. Котов С.В. Психологические детерминанты позитивной мотивации // ИСОМ. 2014. №6-1. С. 196-199.

6. Мингалёва Ж.А., Депутатова Л.Н. Двойственность мотивации интеллектуального труда работников // Вестник ПНИПУ. Социальноэкономические науки. 2016. №2.

7. Пырьев Е.А. Эмоциональные отношения в структуре мотивации человека // Известия РГПУ им. А.И. Герцена. 2013. №155. С. 53-61.

8. Роберт И. Кабаков. R в действии. Анализ и визуализация данных в программе R / Пер. с англ. Полины А. Волковой. М.: ДМК Пресс, 2016.

9. Фетискин Н.П., Козлов В.В., Мануйлов Г.М. Социально-психологическая диагностика развития личности и малых групп. М. Изд-во Института Психотерапии, 2002.

10.Шелехова Л.В. Математические методы в психологии и педагогике: в схемах и таблицах: Учебное пособие. СПб.: Издательство «Лань», 2015.

11. Энциклопедия психодиагностики. Психодиагностика взрослых. Самара: Издательский дом «Бахрах-М», 2009.

12. Andrew J. Elliot and Marcy A. Church. A Hierarchical Model of Approach and Avoidance Achievement Motivation. Journal of Personality and Social Psychology 1997, Inc. 0022-3514/97, Vol. 72, No. 1, pp. 218-232.

13. Delia Mioara Popescu, Ioana Bulei, Viorel Mihalcioiu. The impact of professional identity factors on employee motivation. Proceedings of the 
$8^{\text {th }}$ international management conference "Management challenges for sustainable development", November $6^{\text {th }}-7^{\text {th }}, 2014$, Bucharest, Romania, pp. 907-915.

14. Lazaroiu George. Employee Motivation and Job Performance. Linguistic and Philosophical Investigations, ISSN 1841-2394, Vol. 14, 2015, pp. 97-102.

15. Bard Kuvaas, Robert Buch, Antoinette Weibel, Anders Dysvik, Christina G.L. Nerstad. Do intrinsic and extrinsic motivation relate differently to employee outcomes? Journal of Economic Psychology, Vol. 61, 2017, pp. 244-258.

\section{References}

1. Gordeyeva T.O. Vestnik Moskovskogo universiteta. Seriya 14: Psikhologiya. 2014. №3, pp. 63-78.

2. Gurov V.I. Sukmanov E.V. Vestnik Kurskoy gosudarstvennoy selskokhozyaystvennoy akademii. 2008. №2.

3. Dubovik Yu.V. Elektronnyy vestnik Rostovskogo sotsialno-ekonomicheskogo instituta. 2016. №2.

4. Zamfir K. Udovletvorennost trudom [Job satisfaction]. M.: Politizdat. 1983.

5. Kotov S.V. ISOM. 2014. №6-1, pp. 196-199.

6. Mingaleva Zh.A., Deputatova L.N. Vestnik PNIPU. Sotsialno-ekonomicheskiye nauki. 2016. №2.

7. Pyryev E.A. Izvestiya RGPU im. A.I. Gertsena. 2013. №155, pp. 53-61.

8. Robert I. Kabakov. $R v$ deystvii. Analiz $i$ vizualizatsiya dannykh v programme $R[R$ in action. Analysis and visualization of data in the program R]. M.: DMK Press. 2016.

9. Fetiskin N.P., Kozlov V.V., Manuylov G.M. Sotsialno-psikhologicheskaya diagnostika razvitiya lichnosti i malykh grupp [Socio-psychological diagnosis of personal development and small groups]. M. Izd-vo Instituta Psikhoterapii. 2002.

10. Shelekhova L.V. Matematicheskiye metody v psikhologii i pedagogike: $v$ skhemakh i tablitsakh [Mathematical methods in psychology and pedagogy: in charts and tables]. SPb.: Izdatelstvo «Lan». 2015. 
11. Entsiklopediya psikhodiagnostiki. Psikhodiagnostika vzroslykh [Encyclopedia of psychodiagnostics. Psychodiagnostics of adults]. Samara.: Izdatelskiy dom «Bakhrakh-M». 2009.

12. Andrew J. Elliot and Marcy A. Church. A Hierarchical Model of Approach and Avoidance Achievement Motivation. Journal of Personality and Social Psychology 1997, Inc. 0022-3514/97, Vol. 72, No. 1, pp. 218-232.

13. Delia Mioara Popescu, Ioana Bulei, Viorel Mihalcioiu. The impact of professional identity factors on employee motivation. Proceedings of the $8^{\text {th }}$ international management conference "Management challenges for sustainable development”, November $6^{\text {th }}-7^{\text {th }}, 2014$, Bucharest, Romania, pp. 907-915.

14. Lazaroiu George. Employee Motivation and Job Performance. Linguistic and Philosophical Investigations, Vol. 14, 2015, pp. 97-102.

15. Bard Kuvaas, Robert Buch, Antoinette Weibel, Anders Dysvik, Christina G.L. Nerstad. Do intrinsic and extrinsic motivation relate differently to employee outcomes? Journal of Economic Psychology, Vol. 61, 2017, pp. 244-258.

\section{ДАННЫЕ ОБ АВТОРЕ}

Борисова Ирина Ивановна, аспирант кафедры гуманитарных дисциплин

Таганрогский институт управления и экономики.

ул. Петровская, 45, г. Таганрог, Ростовская обл., 347900, Российская Федераичия

barsik2022@yandex.ru

\section{DATA ABOUT THE AUTHOR}

Borisova Irina Ivanovna, Postgraduate Student of the Department of Humanities

Taganrog Management and Economics Institute

45, Petrovskay Str., Taganrog, Rostov Region, 347900, Russian Federation

barsik2022@yandex.ru 